\title{
Disentangling the effects of management and climate on perennial grass pastures and the degradation that follows multi-year droughts
}

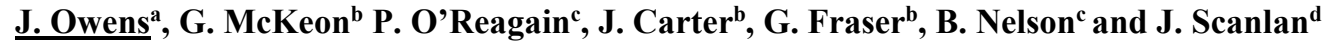 \\ ${ }^{a}$ Centre for Applied Climate Sciences, University of Southern Queensland, Toowoomba, Queensland \\ ${ }^{b}$ Grazing Land Systems Group, Department of Environment and Science, Brisbane, Queensland \\ ${ }^{c}$ Department of Agriculture and Fisheries, Charters Towers, Queensland \\ ${ }^{d}$ Department of Agriculture and Fisheries, Toowoomba, Queensland \\ Email:jo.owens@usq.edu.au
}

\begin{abstract}
Measured data from a long-term grazing trial and insights gained from modelling show that degradation processes following multi-year droughts are not easily reversed, and perennial pastures don't always recover. The combination of drought and overstocking has led to a significant decline in land and pasture condition, with the death of perennial grasses, loss of surface soil protection from ground cover and delayed recovery from drought. Tied up to the loss of desirable perennial grasses is the increase in nondesirable grasses and shrubs, which puts further pressure on the pasture resource available for grazing.

The aim of this study is to use a long-term, high-quality dataset to separate the effects of grazing management and climate on pastures using the biophysical model GRASP. The model captures the effects of both climate and grazing management on the pasture resource and pasture attributes. This involves gaining insights and detecting shifts in vegetation species composition after multi-year wet and dry periods, as well as how the grass species composition changes with the interaction of drought and high stocking rates. The loss of perennial, palatable and productive grass species is important for the grazing industry as it impacts pasture quality, quantity and resilience. When these grass species have been grazed out of the system, animal production can be impacted. The shifts in vegetation composition could also be driving changes in hydrology through reduced infiltration, increased runoff and changed water use patterns by vegetation.
\end{abstract}

The Wambiana grazing trial is regarded as one of the most important field experiments in grazing science because it addresses the major issue of long-term livestock grazing of Queensland's native pastures in a highly variable climate. The trial provides an excellent opportunity to evaluate the effects of climatic (i.e. multi-year wet and dry periods) and grazing management (i.e. fire and stocking rate) on pasture production and resource degradation for a savanna ecosystem (open woodland with perennial native pastures). The simulation study used the GRASP model to represent various processes affected by: a) rainfall variability at multi-year timescales with periods of above average rainfall (Wet Periods 1 and 2) and below average rainfall (Dry Periods 1 and 2); and b) variation in grazing pressure by comparing moderate and heavy continuous stocking rates.

Combining data on stocking rates, field measurements of runoff, pasture growth, biomass, grass basal area, species composition and satellite remote sensed green and dry fractional cover with the GRASP model provides the opportunity for high quality model parameterisation where many of the model parameters are strongly constrained by observational data and previous modelling experience. A well calibrated model is a starting point to investigate the development of new model functions and analyses. We detail how the model calibration was developed, and to what extent we could explain the observed changes in pasture biomass. This work revealed emerging processes in the landscape that we do not currently model, some of which are caused by prolonged droughts and high stocking rates. These processes include the increase in introduced grass species Bothriochloa pertusa and an increase in the native shrub currant bush (of up to $30 \%$ of the land surface area). This work also revealed the need to model the effects of degradation of soils (surface sealing and reduced infiltration) that followed multi-year drought and high utilisation rates. The parameters and insights derived from this study will help inform the modelling of degradation and recovery in grazing landscapes. This study is important for the grazing industry and policy as it impacts on calculations of longterm carrying capacities, pasture biomass and ground cover for sustainable grazing. This study contributes to current applications of GRASP addressing long-term carrying capacity in areas with woody vegetation.

Keywords: Drought, recovery, woody vegetation, savanna ecosystems, parameter estimation 
Owens et al., Disentangling the effects of management and climate on perennial grass pastures and the degradation that follows multi-year droughts.

\section{INTRODUCTION}

An issue commonly raised in the sustainable management of land and pastures in a drought prone climate is how to separate the effects of climate and management. Drought combined with overstocking has led to a significant decline in land and pasture condition in north Queensland in terms of reduced ground cover and a decline in perennial grass species (Tothill and Gillies 1992, O'Reagain et al. 2014). Managing pasture condition and in particular, perennial grass composition, is critical for the long-term sustainability of grazing lands. However, the high year-to-year and multi-year rainfall variability that is a feature of Queensland's climate poses major challenges for land managers, especially in multi-year droughts. Understanding the relative roles of both climate and management is thus critical in improving sustainable management of our land and pasture resources.

The purpose of this study is to separate climate and management effects on pastures using long-term measured data and simulation modelling. One of the main indicators of the impact of grazing is pasture biomass or total standing dry matter. Other indicators are pasture species composition, grass basal area and ground cover. The changes in vegetation species composition after long dry periods and overgrazing are important indicators of pasture degradation and recovery. These shifts in vegetation composition could also drive changes in hydrology through reduced infiltration, increased runoff and soil evaporation and changed water use patterns by vegetation.

Over the last 70 years, field trials (lasting approximately 10-15 years) have provided recommendations on sustainable grazing management. Simulation models have been developed to extrapolate the findings over longer periods using historical climate data and to other locations. The Wambiana grazing trial was set up near Charters Towers in Queensland in 1997 to compare different stocking strategies over time in a highly variable climate (O'Reagain et al. 2018). Measured data from the experiment over the last 23 years provided us with information and insights to model processes such as pasture degradation and recovery. This paper describes the modelling and optimisation approach using field measured pasture biomass and species composition data, complemented with satellite remote sensing data for ground cover. The insights and systems analysis from this study are important for the grazing industry and policy as it impacts on calculations of long-term carrying capacities and pasture biomass available for sustainable grazing.

\section{STUDY AREA AND DATA}

This study uses measured data from one of the longest running field trials in Queensland the Wambiana grazing trial (Figure 1). The experiment was established in 1997 as a large grazing trial with the specific objective of quantifying the relative effects of different grazing strategies on animal production, economic performance and resource condition. The trial is located in an open woodland $70 \mathrm{~km}$ south-west of Charters Towers in north Queensland $\left(20^{\circ} 34^{\prime} \mathrm{S}, 146^{\circ}\right.$ 07'E) (O'Reagain et al. 2018). Long-term average annual rainfall is $627 \mathrm{~mm}$ (calender year, 1890 to 2020), with $80 \%$ of rainfall occurring from October to March. Rainfall is highly variable, ranging from 109 to 1410 $\mathrm{mm} / \mathrm{yr}$. Most of the rainfall occurs in the 3 months of summer $(56 \%$ of the long-term annual average).

The trial site is in the Aristida-Bothriochloa pasture community (Tothill and Gillies 1992) and is an open Eucalyptus-Acacia woodland overlying $\mathrm{C} 4$ tropical native grasses. The trial site has three vegetation-soil associations, but this study focuses on data and modelling from the dominant $(55 \%$ by area $)$ association referred to as Box. The Box landtype is characterised as brown Sodosols and

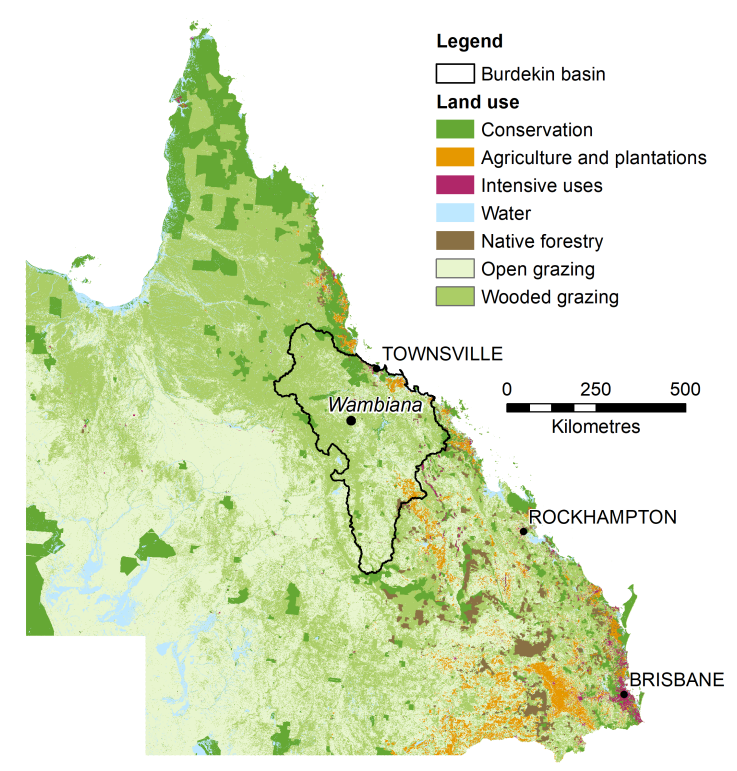

Figure 1. Wambiana Grazing Trial and the Burdekin catchment overlain on the distribution of major land use types in Queensland. The Queensland Land Use Mapping Program (QLUMP) is the best currently available, published in 2019. The wooded vs open grazing is from the woody vegetation extent product from the Remote Sensing Centre based on 2014 imagery. (https://qldspatial.information.qld.gov.au) 
Owens et al., Disentangling the effects of management and climate on perennial grass pastures and the degradation that follows multi-year droughts.

Chromosols and is dominated by Reid River box (Eucalyptus brownii). An understorey of currant bush (Carissa ovata) also covers up to $30 \%$ of the area and is steadily increasing. Pastures on the Box landtype are dominated by native perennial grasses and annual grass species. The exotic, stoloniferous perennial grass, Indian couch (Bothriochloa pertusa), has increased since 2010 in all treatments, particularly in the heavily grazed treatments. The trial has five grazing strategies replicated twice, in paddocks from 93 to 117 ha in size (O’Reagain et al. 2018). Here we focus on two treatments with the greatest contrast:

1. Moderate stocking rate (MSR) - continuously stocked at the estimated long-term carrying capacity of the site to achieve an average of $20-25 \%$ utilisation of expected pasture growth (8 - $10 \mathrm{ha} / \mathrm{AE})$.

2. Heavy stocking rate (HSR) - continuously stocked at about twice the long-term carrying capacity to achieve an average of $40-50 \%$ utilisation of expected pasture growth (4 -5 ha/AE). Stocking rates had to be significantly reduced in a number of years due to drought and the lack of available forage.

Daily interpolated climate data was obtained from SILO (Jeffrey et al. 2001) for Charters Towers weather station 34084. Rainfall data measured at the trial site using pluviometers was used in the simulation study. A rainfall anomaly time series was used to identify drought periods, following the method of Saft et al. (2015), shown in Figure 2, where bars indicate annual rainfall anomalies, and the smoothed line indicates three-year rolling average rainfall anomaly. There were 2 distinct dry and wet periods identified during the study; wet periods 1998 to 2001 and 2007 to 2012; dry periods 2002 to 2006 and 2013 to 2020.

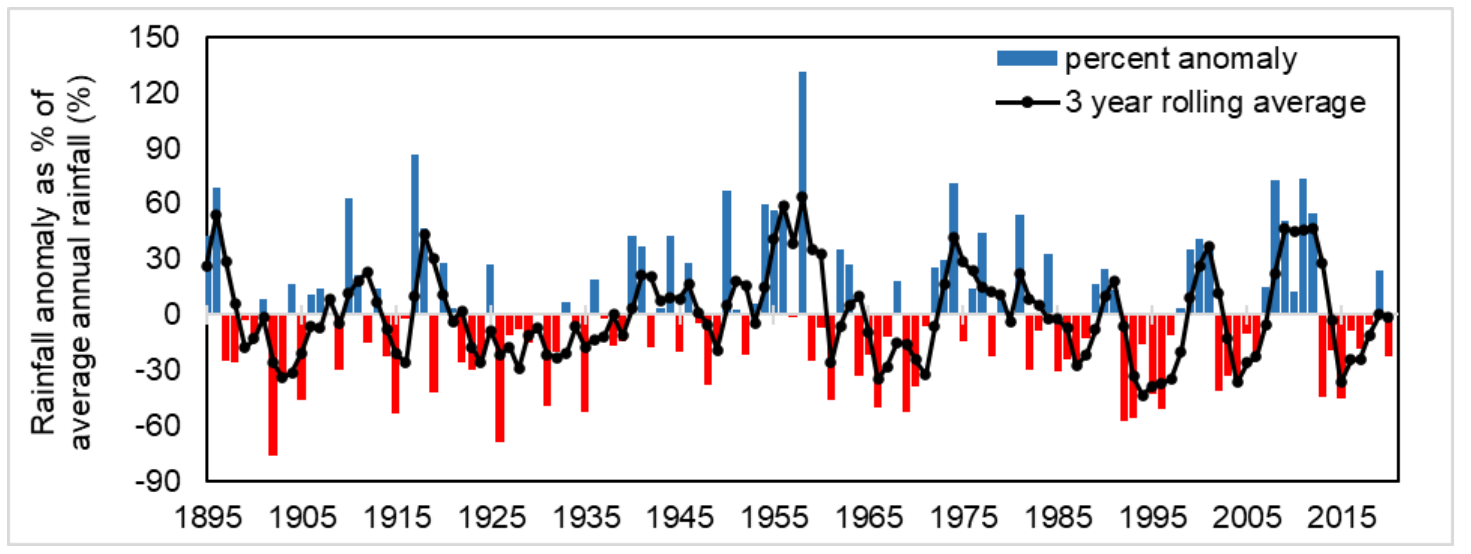

Figure 2. Rainfall anomaly as a \% of average annual rainfall for the water year (30 Sep to 1 Oct) for Charters Tower climate station 34084. Bars indicate annual rainfall anomalies and black line indicates three-year rolling average rainfall. Red bars indicate years falling in identified drought period; blue bars indicate the remainder of the historical period.

Pasture biomass (i.e. total standing dry matter) and species composition was measured annually at the end of the wet season (May) and in the late dry season (October) using the Botanal methodology (Figure 3). Species data was grouped into major functional groups (3P grasses, 2P grasses, Bothriochloa pertusa, annual grasses, and Aristida species). The P's represent grasses that are perennial, productive and palatable and are desirable species in the grazing system and are an important indicator of pasture condition. Pasture composition data guided parameterisation, particularly for minimum nitrogen concentration during the wet and dry periods.

Satellite data for deriving cover was extracted from the United States Geological Survey's Landsat dataset for all single date, cloud free, Landsat based estimates. These data were extracted from Landsat images from 1994 to 2020 from the QLD Government Remote Sensing Centre data store on (26/02/2021). The satellitederived data used for modelling were fractional green cover, total ground cover and persistent green. The persistent green cover data was used in the model as an indicator of change in foliage projected cover.

The satellite-derived observations were also used to compare the ground cover of the grazing trial to the surrounding region ( $25 \mathrm{~km}$ radius) as shown in Figure 4 and available for any property in Queensland from the LongPaddock website (https://www.longpaddock.qld.gov.au/forage). The plot shows narrow bands of high ground cover during the 2 wet periods: 1998 to 2001 and 2007 to 2012 and highlights ground cover was similar to other properties in the region during the wet years. The plots also clearly show the separation of ground cover that occurs during the dry periods: 2002 to 2006 and 2013 to 2020. It also illustrates how ground cover at the Wambiana grazing trial (for all treatments and paddocks) compares to the region. The plot illustrates the effects of climate during the wet and dry periods, with narrow bands during the wet periods and a wider range of ground cover during the dry periods. It is in this wider range of ground covers during the dry periods where the effects of management can be investigated. 
Owens et al., Disentangling the effects of management and climate on perennial grass pastures and the degradation that follows multi-year droughts.
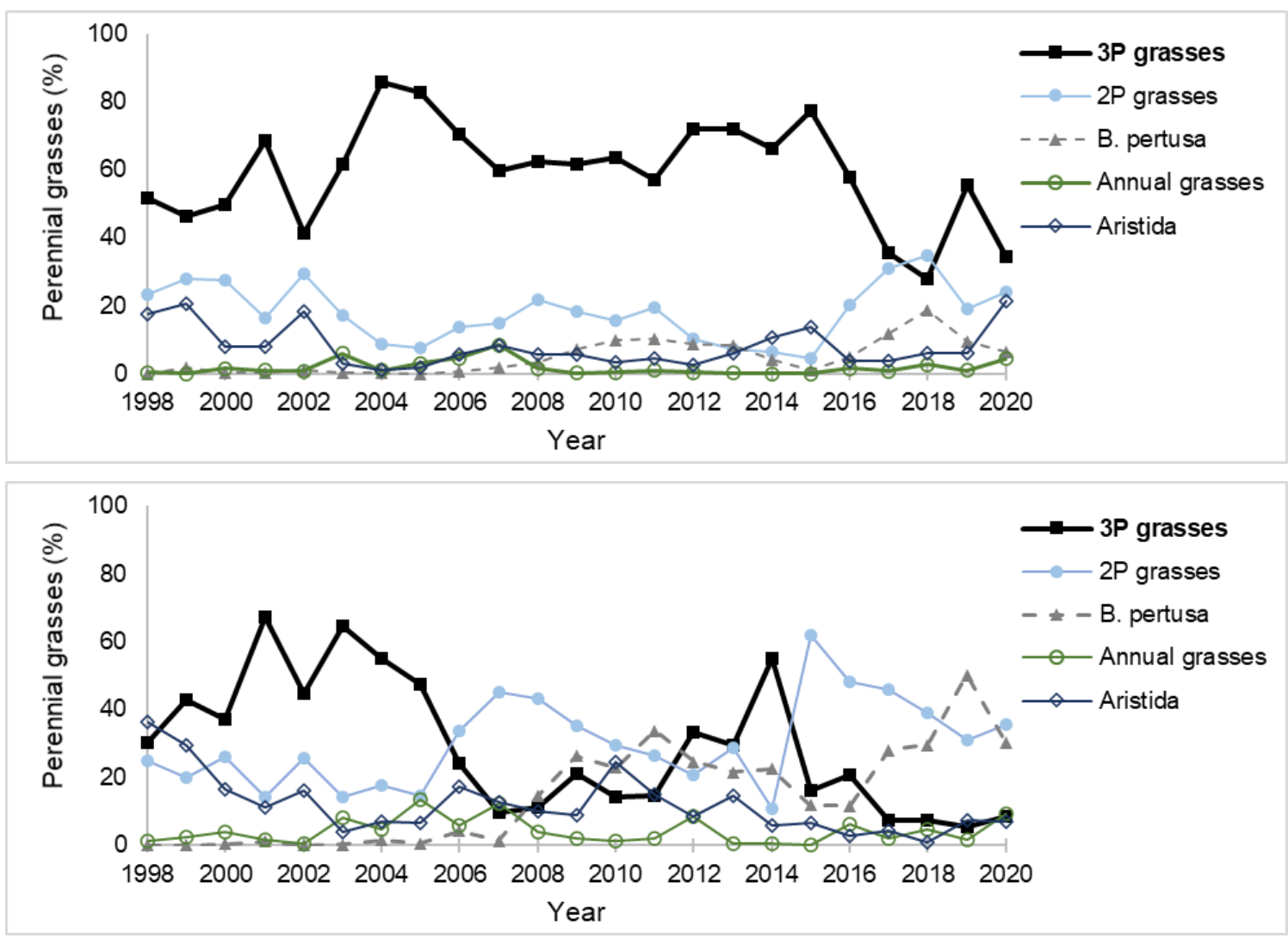

Figure 3. Measured pasture composition of grasses at the end of the wet season in May for (a) moderate and (b) heavy stocking rate paddocks for the Box landtype at the Wambiana grazing trial. The proportion of 3P grasses is an important indicator of pasture condition and the moderately stocked treatment has a higher proportion of $3 \mathrm{P}$ grasses compared to the heavily stocked treatment. The introduced grass, Bothriochloa pertusa is increasing in both treatments, and is higher in the heavy stocked treatment.

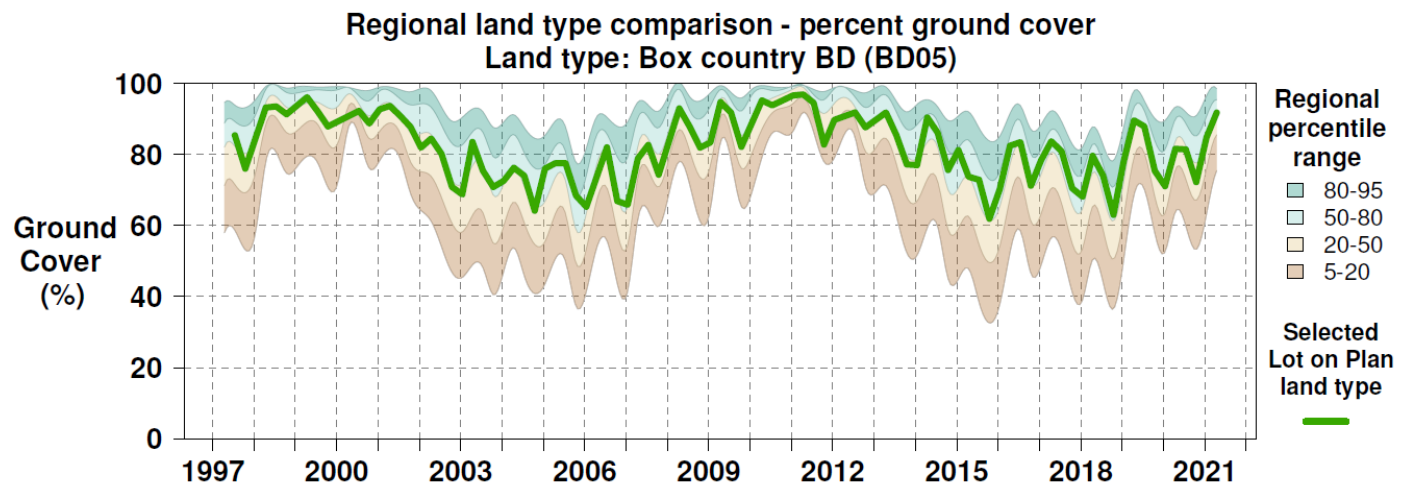

Figure 4. Regional land type comparison of percent ground cover for the Box landtype at Wambiana, compared to the region. The green line represents the average of all treatments in the grazing trial.

\section{MODEL DESCRIPTION}

GRASP is a biophysical model of soil water balance, pasture growth and animal production developed for northern Australian grasses in wooded and non-wooded systems (Day et al. 1997, Zhang et al. 2021). The Cedar version of GRASP (version 1.2) was used for all model simulation and is the Linux version that underpins the core model used on other platforms such as the Windows version and other operational versions, such as FORAGE (Zhang et al. 2021). Practical applications for the model include the calculation of long-term livestock carrying capacity for grazing properties in Queensland using GRASP and its parameter sets to combine knowledge from field experimentation, land resource surveys, remote sensing of vegetation and grazier estimates of carrying capacity (Zhang et al. 2021). 
Owens et al., Disentangling the effects of management and climate on perennial grass pastures and the degradation that follows multi-year droughts.

Driving data such as climate, stock numbers, stock live weight, and fire incidence were assembled for each treatment and entered into the GRASP management records data format. In addition, field observations of pasture biomass, composition, grass basal area and satellite cover were entered into the GRASP management record format and checked for errors. These measured datasets are invaluable in calibrating, testing and model improvement as well as ground truthing remote sensing data.

The starting point for growth related model parameters was the analysis of measurements from exclosure plots established at the grazing trial. Pasture growth, soil moisture and nitrogen were measured through the growing season using the GUNSYNpD methodology which was designed to collect a minimum dataset for estimating key pasture growth and soil parameters (Day et al. 1997). Runoff measurements from small catchments within the grazing trial were used to ensure that modelled runoff was within the range of observations. We estimated parameters using a Differential Evolution method (Storn and Price 1997), which is a simple and efficient method for global optimisation. The objective function was the root mean square error of daily pasture biomass predictions. Parameters were optimised to minimize the objective function, with parameters constrained within sensible limits based on prior knowledge from a wider network of grazing trials and grass production sites to calibrate the model using 23 years of measured pasture biomass data. The two parameters optimised were the potential pasture regrowth (parameter 6) and the soil moisture threshold for the cessation of pasture growth (parameter 149). We used the moderate stocking rate treatment for calibration and applied the calibrated model to the high stocking rate treatment to reveal degradation signals once the effects of climate and livestock consumption were accounted for.

\section{RESULTS AND DISCUSSION}

Improvement in pasture biomass simulated by GRASP was obtained through optimisation of two parameters with measured data for the moderate stocking rate treatment. Optimised parameters were then run for the heavy stocking rate treatment, with reasonable predictions of pasture biomass, showing that grazing management effects could be explained by consumption of pasture dry matter (Figure 5). Changes in foliage projected cover used in the simulation explained some of the variation in pasture biomass. This was particularly important after pasture burning, when foliage projected cover was greatly reduced.

The model calibration of the moderate stocking rate treatment was reasonable but did not capture all aspects of the measured data (Figure 5a). Simulations of standing dry matter were consistently higher than measured values for the last 5-7 years of the trial for both treatments, even after stocking rate was reduced in the high stocking rate treatment during the drought when severe degradation occurred (Figure $5 \mathrm{~b}$ ). The low pasture biomass in both treatments indicates that degradation processes of both the pasture and soil resource were not being captured after the last drought. Trial data shows that pasture composition had changed before this effect became apparent in the simulations, indicating that the degradation processes, in addition to composition change (Figure 3) were already in progress.

The likely causes of the over-prediction of pasture biomass in Figure 5 are: (1) reduced tussock densities as a result of low rainfall and associated higher grazing pressure; (2) surface sealing and reduced infiltration capacity (Fraser and Stone 2016); and (3) increasing density of shrub cover (currant bush) resulting in greater competition for soil water and nutrients impacting pasture growth. The mathematical representation of these processes is the subject of current research. In addition, we are aware of other factors affecting pasture biomass such as increased detachment rates, errors in accurately measuring biomass in the prostrate form of Bothriochloa pertusa, and livestock consuming an increased forb/annual grass component prior to field measurements in May.

The differences in pasture biomass between moderate and heavy stocking rate treatments allow some assessment of climate and management effects. The simulations of pasture biomass with constant parameters over the 23 years for the moderate stocking rate explain the 'potential' effects of variable rainfall on biomass. The biomass differences between stocking rate treatments in both wet periods and most of the first dry period are simulated/explained by the increased consumption (and trampling) from higher stocking rates.

In contrast, the lower pasture biomass at the end of dry period 1 and most of dry period 2 (compared to the 'potential') demonstrated the decrease ('degradation') in pasture production caused by the heavy grazing pressure, particularly in the prolonged dry periods. For both moderate and heavy stocked treatments, the lower pasture biomass (compared to the potential production) at the end of dry period 2 indicate that recovery of pasture production back to potential did not occur. In particular, there was a lack of recovery in the heavy stocking rate treatment even though the grazing pressure had been greatly reduced, suggesting longer lasting effects on the resource with heavy utilisation. 
Owens et al., Disentangling the effects of management and climate on perennial grass pastures and the degradation that follows multi-year droughts.

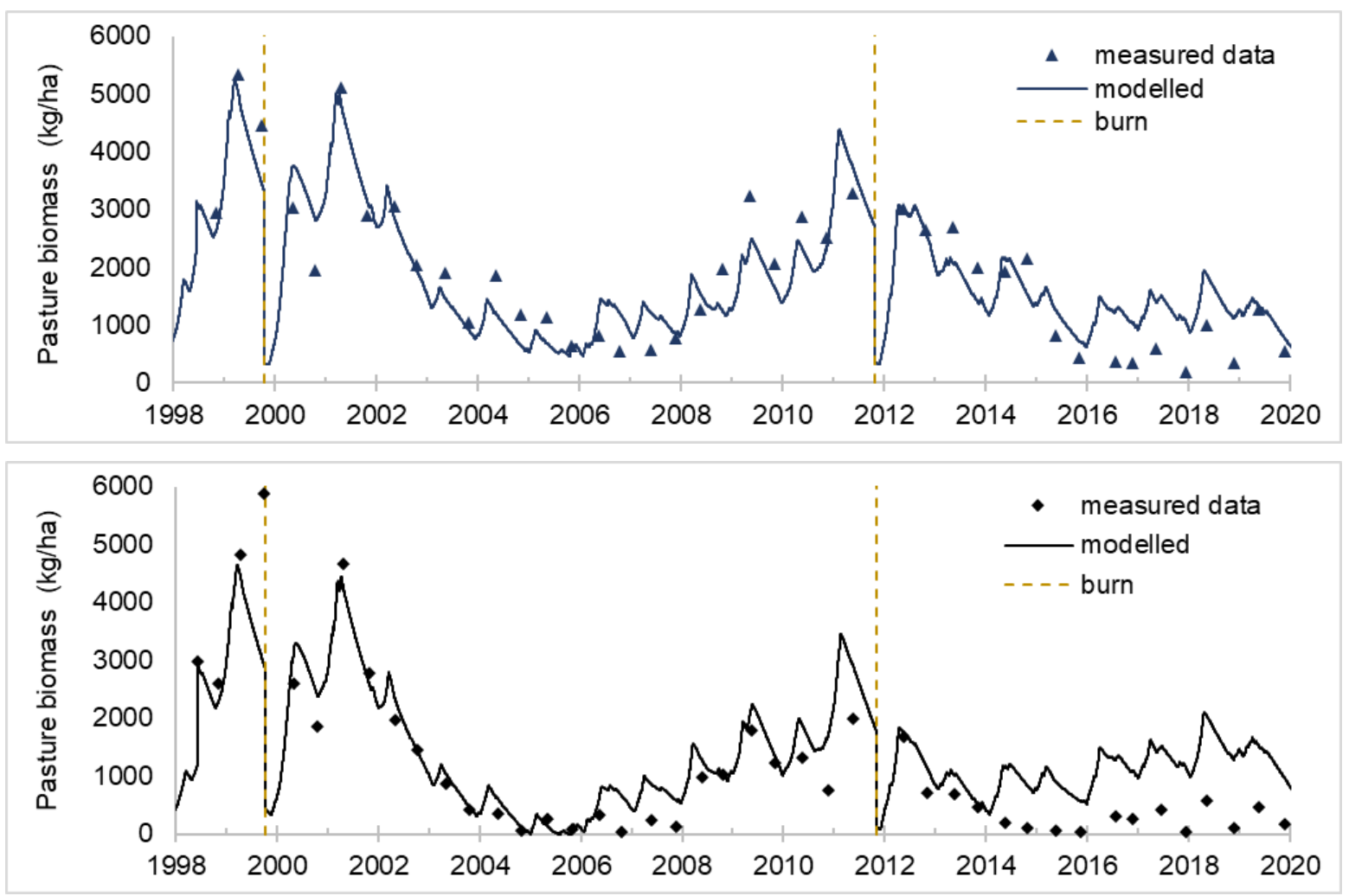

Figure 5. Predicted and measured pasture biomass for two treatments, (a) moderate stocking rate (top) and (b) high stocking rate (bottom). The site was burnt in October 1999 and 2011 to manage woody vegetation.

Comparison of simulated green cover and the satellite-derived green cover were in general agreement (Figure 6). The annual seasonal wet and dry cycle of green cover was well simulated by the modelled processes of pasture growth and senescence which are strongly linked to soil moisture. Peak observed and simulated green cover were similar in the two wet periods and at the start of the two dry periods with some under prediction consistent with under prediction of pasture biomass. However, in the later years of the two dry periods, peak green cover was under predicted in contrast to the over prediction of pasture biomass. Possible causes could be changes in the relationship of green cover to green biomass as a consequence of changes in pasture sward structure and/or changes in pasture species composition associated with heavier grazing pressure.

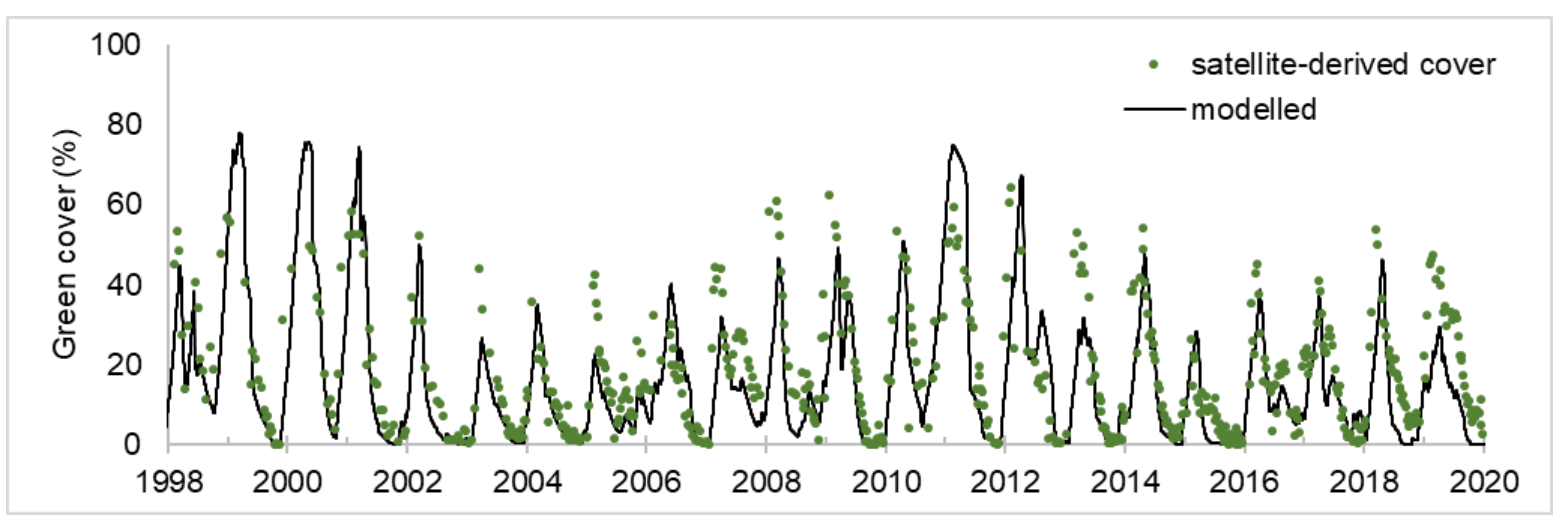

Figure 6. Predicted green cover for the moderate stocking rates treatment plotted with observed satellitederived green cover.

A scoping study was carried out using a systems analysis approach to investigate the biophysical processes operating that were not currently captured by the dynamic model. The wet and dry periods were separated during the simulation with separate sets of parameters and model resets. This approach provided insights on the processes driving pasture growth during the wet and dry periods. The study revealed that 4 major parameters could be used to simulate pasture biomass reasonably well compared to measured data, particularly in the last dry period (2014 to 2020) which was overpredicted by the dynamic model. The 4 
Owens et al., Disentangling the effects of management and climate on perennial grass pastures and the degradation that follows multi-year droughts.

parameters were potential nitrogen uptake; minimum nitrogen concentration in pasture dry matter; potential pasture regrowth; and soil moisture threshold for the cessation of pasture growth.

For the optimisation used in Figure 5, we calibrated only two of these parameters for the full 23 years of the trial without any separation of wet and dry periods (potential pasture regrowth and soil moisture threshold parameters). The next steps are the construction of sub-models in GRASP dynamically linking variation in these parameters with pasture composition and perennial tussock density reflecting the effects of multi-year rainfall sequences and grazing management (stocking rates and fire).

\section{CONCLUSION}

This study provides parameterisation for improving the modelling of pastures in savanna ecosystems, especially during prolonged droughts. The findings of our study will contribute to current applications of GRASP addressing the issue of long-term carrying capacity and pasture biomass available for sustainable grazing. We demonstrate how satellite-derived vegetation cover data can be used to evaluate and support modelling of ground cover in grazing systems. Modelled and measured pasture biomass agreed well after model optimisation and provided insights on missing processes, giving us more confidence in identifying degradation and recovery signals. This study revealed several known but unrepresented processes in the GRASP model, which is the subject of current research. However, the long-term datasets and modelling can help diagnose the patterns of degradation and provide a platform for the generation and testing of algorithms that more accurately describe aspects of the degradation process.

\section{ACKNOWLEDGEMENTS}

This work would not have been possible without the long-term dataset from the Wambiana grazing trial cofunded by DAF and Meat and Livestock Australia. We are deeply grateful to the Lyons family, Wambiana, for hosting the trial site, and to John Bushell and technical staff at DAF for data collection. We are grateful to Mathew Pringle for python scripts to estimate fractional cover from Landsat, Robert Denham for the Ground Cover Regional Comparison Report, and to Tessa Chamberlain from the Paddock to Reef Team for the Queensland Land Use Mapping and woody vegetation extent. We acknowledge funding from the Queensland Drought and Climate Adaptation Program (DCAP) and the Queensland Reef Water Quality Program.

\section{REFERENCES}

Day, K.A., McKeon, G.M. and Carter, J.O. (1997). Evaluating the risk of pasture and land degradation in native pastures in Queensland, Final Report on DAQ124A to RIRDC (six volumes).

Fraser, G.W. and Stone G.S. (2016) The effect of soil and pasture attributes on rangeland infiltration rates in northern Australia. The Rangeland Journal 38, 245-259.

Jeffrey, S.J., Carter, J.O., Moodie, K.B. and Beswick, A.R. (2001) Using spatial interpolation to construct a comprehensive archive of Australian climate data. Environmental Modelling \& Software 16(4), 309-330.

O’Reagain, P.J., Scanlan, J., Cowley, R., Hunt, L. and Walsh, D. (2014). Sustainable grazing management for temporal and spatial variability in north Australian rangelands - a synthesis of the latest evidence and recommendations. The Rangelands Journal 36: 223-232.

O’Reagain, P., Bushell, J., Pahl, L., and Scanlan, J. (2018). Wambiana Grazing Trial Phase 3: Stocking Strategies for Improving Carrying Capacity, Land Condition and Biodiversity Outcomes. Meat and Livestock Australia Final Report to Project B.ERM.0107 (Meat and Livestock Australia: North Sydney, NSW.); 149pp.

Saft, M., Western, A.W., Zhang L., Peel, M.C. and Potter N.J. (2015). The influence of multiyear drought on the annual rainfall-runoff relationship: An Australian perspective. Water Resources Research. 51, 24442463. https://doi.org/10.1002/2014WR015348

Storn, R. and Price, K. (1997). Differential evolution - a simple and efficient heuristic for global optimization over continuous spaces. Journal of Global Optimization, 11, 341-359.

Tothill J.C. and Gillies C. (1992) 'The pasture lands of northern Australia. Their condition, productivity and sustainability.' (Tropical Grassland Society of Australia: Brisbane)

Zhang B., Fraser G., Carter J., Stone G., McKeon G., Whish G., Wilcock J. (2021). An online system for assessing long-term carrying capacity for Queensland grazing properties: Part 2 modelling and outputs (accepted: The Rangelands Journal). 